\title{
Comparison of the Serum Levels of Interferon- $\alpha$ in the Patients With Crimean-Congo Hemorrhagic Fever Based on Disease Severity
}

\author{
Maliheh Metanat ${ }^{1}$, Masoud Salehi ${ }^{1}$, Anita Ale-Nabi ${ }^{1}$, Masoume Noori-Jangi ${ }^{1}{ }^{*}$, Alireza Noori-Jangi ${ }^{2}$, Mehdi \\ Noori-Jangi ${ }^{3}$, Nahid Sepehri-Rad ${ }^{1}$, Farshid Fathi ${ }^{4}$ \\ ${ }^{1}$ Infectious Diseases and Tropical Medicine Research Center, Zahedan University of Medical Sciences, Zahedan, Iran \\ ${ }^{2}$ Veterinary Medicine, Zabol University, Zabol, Iran \\ ${ }^{3}$ Internal Assistant, Department of Hematology, Ahvaz Jundishapur University of Medical Sciences, Ahvaz, Iran \\ ${ }^{4}$ Department of Immunology, School of Medicine, Isfahan University of Medical Sciences, Isfahan, Iran
}

\section{*Correspondence to Masoume Noori-Jangi; Email: dr.noori74@yahoo.com}

Received August 1, 2016 Revised September 24, 2016 Accepted October 2, 2016 Published online October 8, 2016

Please cite this article as follows: Metanat M, Salehi M, Ale-Nabi A, et al. Comparison of the serum levels of interferon- $\alpha$ in the patients with CrimeanCongo hemorrhagic fever based on disease severity. Int J Basic Sci Med. 2016;1(2):5862. doi:10.15171/ ijbms.2016.13.

\begin{abstract}
Introduction: Crimean-Congo hemorrhagic fever (CCHF) is an acute viral and potentially fatal disease that is endemic in the south east of Iran, especially Sistan and Baluchestan. This study aimed to measure the serum levels of interferon- $\alpha$ (IFN- $\alpha$ ) in the patients with CCHF, considering the disseminated intravascular coagulation (DIC) severity. The second aim was to determine the correlation between the serum levels of IFN- $\alpha$ and DIC severity using the guidance of diagnosis and treatment of the CCHF.

Methods: Thirty-seven patients with CCHF were studied. The diagnosis was made, based on the detection of viral RNA by real time-polymerase chain reaction (RT-PCR) and by positive serology. These patients, based on the severity of DIC, were divided into two groups. The serum levels of IFN- $\alpha$ were measured by the enzyme-linked immunosorbent assay (ELISA) method and compared between these two groups. Data analysis was performed using the SPSS 20.0 and non-parametric statistical tests were used for analyses.

Results: The mean serum levels of IFN- $\alpha$ were lower in the patients with CCHF on the first day compared to the fifth day of admission $(P<0.008)$. There was a significant relationship between the serum levels of IFN- $\alpha$ and DIC severity, as the level of IFN- $\alpha$ was lower in the patients with overt DIC $(P<0.001)$. The serum level of IFN- $\alpha$ in the patients with the overt DIC was 1.04 pg/ dL with $90 \%$ specificity and $88 \%$ sensitivity.

Conclusion: The serum levels of IFN- $\alpha$ were lower in the patients with severe CCHF, and their evaluation may be used as a marker for the diagnosis of disease severity.

Keywords: Crimean-Congo hemorrhagic fever, Disseminated intravascular coagulation, Serum interferon- $\alpha$
\end{abstract}

\section{Introduction}

Crimean-Congo hemorrhagic fever $(\mathrm{CCHF})$ is a viral disease that is transmitted to humans by Hyalomma ticks or by handling the blood or secretions of infected people or domestic animals. ${ }^{1}$ Incidence of disease increases in the spring when Hyalomma marginatum is activated by the temperature rising. ${ }^{2}$ The disease is observed from the eastern China to Russia, the Balkans, Central Asia, and Africa. ${ }^{2}$ The incubation period lasts 7-13 days after infection, although the period of more than 13 days has also been documented. ${ }^{3}$ The prehemorrhagic phase lasts 3-7 days, and is characterized by a rapid rising of fever, fatigue, cephalalgia, and dizziness. In addition, nausea, vomiting, and diarrhea may be observed. ${ }^{4}$ Different cases of CCHF progression to the hemorrhagic phase is characterized by petechiae, ecchymosis, epistaxis, and gingival hemorrhage, and often includes gastrointestinal hemorrhage which lasts 2-3 days. ${ }^{5} \mathrm{CCHF}$ is a severe hemorrhagic fever with shock, DIC, and frequent extensive bleeding. ${ }^{6}$ This virus belongs to the genus Nairovirus and family Bunyaviridae which causes severe disease, with the reported case fatality rate ranging from $15 \%$ to $30 \%{ }^{7}$ Lethal illness is attribut-

Copyright (C) 2016 The Author(s); Published by Zabol University of Medical Sciences. This is an open-access article distributed under the terms of the Creative Commons Attribution License (http://creativecommons.org/licenses/by/4.0), which permits unrestricted use, distribution, and reproduction in any medium, provided the original work is properly cited. 
ed to extant infection, severe hemorrhage, and finally disseminated intravascular coagulation (DIC). ${ }^{8}$ About the pathology, DIC severity that is observed during disease can be used as an important parameter. ${ }^{9}$ DIC is characterized by the systemic activation of blood coagulation that generates intravascular thrombin and fibrin resulting in the thrombosis of small- to medium sized vessels and ultimately organ dysfunction and severe bleeding. ${ }^{10}$ Nonovert (early) DIC is a subtle hemostatic dysfunction that has not yet reached the decompensation stage, as in overt DIC. ${ }^{10}$ Although the pathogenesis of CCHF is poorly understood, results of recent studies suggest that measurement of the inflammatory parameters including cytokines and serum ferritin levels may be used as markers of the pathogenesis. ${ }^{11}$ Though completely unclear, the proliferation and differentiation of virus is increased when the serum interferon- $\alpha$ (IFN- $\alpha$ ) level is low. Forty-eight hours after infection, secretion of interferon initiates acting as defense mechanism against virus. However, studies on the serum level of IFN- $\alpha$ in association with CCHF is limited. Therefore, this study aimed to measure the serum levels of IFN- $\alpha$ in the patients with CCHF regarding DIC severity. The second aim was to determine any correlation between the serum levels of IFN- $\alpha$ and DIC severity using the guidance of diagnosis and CCHF treatment.

\section{Methods}

Serum samples were obtained from 50 patients on the first and fifth days of admission to the hospital from 2013 to 2014. The patients were diagnosed with CCHF at the Boo-Ali hospital, Zahedan, Iran. The serum samples were stored at $-40^{\circ} \mathrm{C}$ for the analysis and measurement of IFN-a. In addition, part of each sample was immediately sent to the Pasteur Institute, Tehran, Iran, for carrying out RT-PCR. Patients who had positive polymerase chain reaction (PCR) assay, were included in the study. Moreover, the serologic tests were used for the diagnosis of CCHF. Based on the abovementioned tests, 37 out of 50 patients were selected for this study. Laboratory tests on the serum samples consisted of platelet count, prothrombin (PT), international normalized ratio (INR), IFN- $\alpha$ and D-dimer. Measurement of the serum levels of IFN- $a$ was done by GSCIENCE kit (GSCIENCE, ELISA Assay, USA). Analyses of D-dimer levels (VIDAS, Enzyme Linked Fluorescent Assay, USA) and fibrinogen levels were done using the kit purchased from Mahsayaran (Mahsayaran, Iran). Severity of DIC was scored, based on the scoring system of International Society of thrombosis and Haemostasis (ISTH) (9. 19) (Table 1).

Based on the ISTH criteria, a score of 5 or higher was specified as overt DIC and a score of lower than 5 was considered as non-overt DIC. After determining DIC severity, patients were divided into two groups including non-overt and overt. Finally, the serum levels of IFN- $a$ of two groups were evaluated and compared.

Analyses of collected data were performed using SPSS version 20.0. Fisher exact test was used when the data were reliable. The data were analyzed using $t$ tests and one-way analysis of variance (ANOVA). A $P$ value less than 0.05 was considered significant.

\section{Results}

Thirty-seven of patients with CCHF were admitted to the Boo-Ali hospital, Zahedan, Iran, between 2013 and 2014. The diagnosis was made, based on the detection of viral RNA by real time-polymerase chain reaction (RTPCR) and by positive serology. The mean age of patients was $31.08 \pm 12.23$. Thirty-one $(83.8 \%)$ patients were male. The mean age of males and females were insignificant $(P>0.05$; Table 2$)$.

There was significant difference in the mean serum levels of IFN- $a$ between days following admission and it was lower on day 1 of admission (Table 3 ).

However, there was insignificant difference in the mean serum levels of IFN- $\alpha$ between males and females on days 1 and 5 of admission $(P>0.05$; Table 4$)$. In addition, the mean serum levels of IFN- $\alpha$ were insignificant $(P>0.05$ for age groups on days 1 and 5 of admission, respectively, Table 5).

As shown in Table 4, there was significant difference in the serum levels of IFN- $a$ between two groups of patients, based on the severity of the DIC $(P<0.001)$. In addition, the serum levels of IFN- $a$ were lower in the patients with

Table 1. Scoring Methods for DIC, Based on the ISTH

\begin{tabular}{lcc}
\hline Variable & Range & Score \\
\hline & $>100000$ per $\mathrm{mm}^{3}$ & 0 \\
Platelet count (Plt) & $50000-100000$ & 1 \\
& $<50000$ & 2 \\
Prolonged prothrombin & $<3 \mathrm{~s}$ & 0 \\
time (PT) & $3-6 \mathrm{~s}$ & 1 \\
& $>6 \mathrm{~s}$ & 2 \\
Fibrinogen & $>100 \mathrm{mg} / \mathrm{dL}$ & 0 \\
& $<100 \mathrm{mg} / \mathrm{dL}$ & 1 \\
D-dimer normal $<0 / 5 \mu \mathrm{g} / \mathrm{mL}$ & $0.5-1 \mu \mathrm{g} / \mathrm{mL}$ & 0 \\
& $1-3 \mu \mathrm{g} / \mathrm{mL}$ & 1 \\
\hline
\end{tabular}

Table 2. The Mean Age and Sexual Distribution of the Patients

\begin{tabular}{lcccc}
\hline Sex & $\begin{array}{c}\text { No. of } \\
\text { Patients }\end{array}$ & Percent & Age (Mean \pm SD) & $\boldsymbol{P}^{\mathrm{a}}$ \\
\hline Male & 31 & 83.8 & $30.19 \pm 11.46$ & 0.32 \\
Female & 6 & 16.2 & $35.67 \pm 6.07$ & 0.32 \\
Total & 37 & 100 & & \\
\hline
\end{tabular}

andependent samples $t$ test.

Table 3. The Mean Serum Levels of IFN- $\alpha$, Based on the Sex and Days Following Admission

\begin{tabular}{llccc}
\hline $\begin{array}{l}\text { Day of } \\
\text { Admission }\end{array}$ & Sex & $\begin{array}{c}\text { No. of } \\
\text { Patients }\end{array}$ & $\begin{array}{c}\text { Serum Levels of } \\
\text { IFN- } \boldsymbol{\alpha}(\mathbf{p g} / \mathbf{d L})\end{array}$ & $\boldsymbol{P}^{\mathrm{a}}$ \\
\hline \multirow{2}{*}{1 (37 patients) } & Male & 31 & $2.01 \pm 1.34$ & \\
& Female & 6 & $1.56 \pm 1.73$ & 0.47 \\
& Male & 20 & $2.31 \pm 1.44$ & \multirow{2}{*}{5 (23 patients) } \\
& Female & 3 & $3.38 \pm 1.24$ & \\
\hline
\end{tabular}

${ }^{\text {a }}$ Independent samples $t$ test. 
Table 4. The Mean of Serum Levels of IFN- $\alpha$, Based on DIC Severity

\begin{tabular}{|c|c|c|c|c|c|}
\hline Day of Admission & DIC Severity & No. of Patients & Percent & Serum Levels of IFN-a (pg/dL) & $\boldsymbol{P}^{\mathrm{a}}$ \\
\hline \multirow{2}{*}{1 (37 patients) } & Overt DIC & 27 & 73 & $2.49 \pm 1.22$ & \multirow{2}{*}{$<0.001$} \\
\hline & Non-overt DIC & 10 & 27 & $0.45 \pm 0.37$ & \\
\hline \multirow{2}{*}{5 (23 patients) } & Overt DIC & 17 & 73.9 & $2.94 \pm 1.34$ & \multirow{2}{*}{$<0.001$} \\
\hline & Non-overt DIC & 6 & 26.1 & $1.05 \pm 0.4$ & \\
\hline
\end{tabular}

${ }^{a}$ Independent samples $t$ test.

Table 5. The Mean of Serum Levels of IFN- $\alpha$, Based on Age and Days Following Admission

\begin{tabular}{llcc}
\hline Day of admission & Age & No. of Patients & Serum Levels of IFN-a (pg/dL) \\
\hline \multirow{2}{*}{1 (37 patients) } & $<25$ years & 18 & $2.08 \pm 1.49$ \\
& $25-40$ years & 9 & $1.93 \pm 1.26$ \\
& $>40$ years & 10 & $1.68 \pm 1.43$ \\
5 (23 patients) & $<25$ years & 11 & $2.37 \pm 1.61$ \\
& $25-40$ years & 7 & $2.11 \pm 1.43$ \\
\hline
\end{tabular}

ane-way ANOVA.

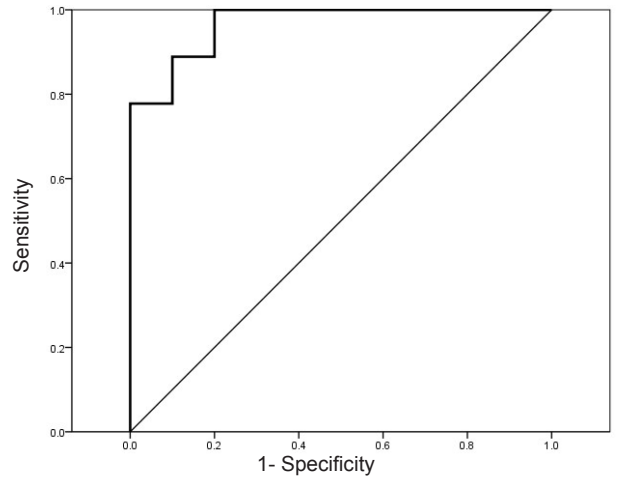

Figure 1. Receiver Operating Characteristics (ROC) Curve in Association With the Performance of the Serum Levels of IFN- $\alpha$ (on Day 1 of Admission) as the Predictor of DIC Severity.

overt DIC compared to the patients with non-overt DIC. To determine the favorable threshold of the serum levels of IFN- $\alpha$ as the predictor of the DIC severity, the receiver operating characteristics (ROC) curve was used. The serum levels of IFN-a $1.04 \mathrm{pg} / \mathrm{dL}$, on day 1 and $1.1 \mathrm{pg} / \mathrm{dL}$ on day 5 of admission were selected as the threshold levels for the prediction and diagnosis of DIC severity (Figures 1 and 2).

Based on these figures, the levels lower than this threshold showed overt DIC and higher levels of this threshold were associated with non-overt DIC. In addition, based on this threshold, the sensitivity and the specificity of the serum levels of IFN- $\alpha$ for diagnosis and prediction were estimated (Tables 6 and 7).

We used the ROC to determine the favorable threshold of the serum levels of IFN- $\alpha$ for the prediction of final state of disease (fatal or non-fatal) (Figure 3 ).

The serum level of IFN- $\alpha(1.4 \mathrm{pg} / \mathrm{dL})$, on day 1 of admission was selected as the threshold level for the prediction and diagnosis of final state of disease. Based on the figures, the levels lower than this threshold led to 100 non-fatality. In addition, based on the threshold, the sensitivity and

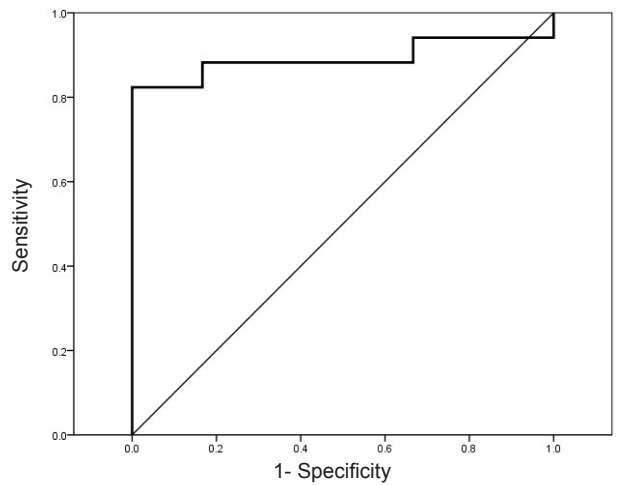

Figure 2. Receiver Operating Characteristics Curve in Association With the Performance of the Serum Levels of IFN- $\alpha$ (on Day 5 of Admission) as the Predictor of Severity.

specificity of the serum levels of IFN-a was estimated as the final state of disease.

\section{Discussion}

This study aimed to measure the serum levels of IFN- $a$ in the patients with CCHF considering the DIC severity. The second aim was to determine any correlation between the serum levels of IFN- $\alpha$ and DIC severity using the guidance of diagnosis and treatment of CCHF. CCHF is a viral disease that is transmitted to humans by Hyalomma ticks or by handling the blood or secretions of infected people or domestic animals. ${ }^{1}$ The incubation period of CCHF depends on the mode of transmission and it increases from 2 to 7 days following a tick bite, or up to 10 to 14 days after blood transfusion or organ transplantation. ${ }^{12}$ Pre-hemorrhage stage suddenly occurs, accompanied with some symptoms including fever, chills, severe muscular pains, headache, vomiting, and pain in the epigastric and lumbar regions. ${ }^{12}$ Leukopenia and thrombocytopenia in the patients with acute febrile syndrome is characterized in the laboratory. ${ }^{8}$ This phase lasts 3-7 days and the hemorrhagic phase lasts 3-5 days. ${ }^{8}$ 
Table 6. DIC Severity, Based on the Threshold of the Serum Levels of IFN- $\alpha$ on Day 1 of Admission

\begin{tabular}{lccc}
\hline \multirow{2}{*}{$\begin{array}{l}\text { Serum Levels of } \\
\text { IFN-a (pg/dL) }\end{array}$} & \multicolumn{2}{c}{ DIC Severity } & No. of Patients \\
\cline { 2 - 3 } & Overt DIC & Non-overt DIC & \\
\hline Lower than 1.04 & 9 & 3 & 12 \\
Higher than 1.04 & 1 & 24 & 25 \\
Total prevalence & 10 & 27 & 37 \\
\hline
\end{tabular}

Table 7. DIC Severity, Based on the Threshold of the Serum Levels of IFN- $\alpha$ on Day 5 of Admission

\begin{tabular}{llll}
\hline \multirow{2}{*}{$\begin{array}{l}\text { Serum Levels of } \\
\text { IFN-a }(\mathbf{p g} / \mathbf{d L})\end{array}$} & \multicolumn{2}{c}{ DIC Severity } & No. of Patients \\
\cline { 2 - 3 } & Overt DIC & Non-overt DIC & 7 \\
\hline Lower of 1.1 & 5 & 2 & 16 \\
$\begin{array}{l}\text { Higher of } 1.1 \\
\begin{array}{l}\text { Total number of } \\
\text { patients }\end{array}\end{array}$ & 1 & 15 & 23 \\
\hline
\end{tabular}

Table 8. Outcome of Disease, Based on the Threshold of the Serum Levels of IFN- $\alpha$

\begin{tabular}{|c|c|c|c|}
\hline \multirow{2}{*}{$\begin{array}{l}\text { Serum Levels of } \\
\text { IFN-a (pg/dL) }\end{array}$} & \multicolumn{2}{|c|}{ DIC Severity } & \multirow{2}{*}{ No. of Patients } \\
\hline & Non-fatal Cases & Fatal Cases & \\
\hline Lower than 1.4 & 13 & 3 & 16 \\
\hline Higher than 1.4 & 21 & 0 & 21 \\
\hline $\begin{array}{l}\text { Total number of } \\
\text { patients }\end{array}$ & 34 & 3 & 37 \\
\hline
\end{tabular}

Lethal illness is attributed to extant infection, severe hemorrhage, and finally DIC. ${ }^{8}$ In different studies, factors that affect the disease severity were evaluated. In one study, laboratory parameters to determine DIC severity consisted of platelet counts, biochemical parameters (aspartate aminotransferase [AST], alanine aminotransferase [ALT]), and creatine phosphokinase (CK). ${ }^{5}$ Ergonul et al observed that the serum levels of interleukin-6 (IL-6) and tumor necrosis factor- $\alpha$ (TNF- $\alpha$ ) were significantly higher in the patients with fatal CCHF than in the patients with non-fatal CCHF. ${ }^{8}$ However, the serum levels of IL-10 were not significantly different between two groups. Concerning the pathology, DIC severity that was observed during disease can be used as an important parameter. ${ }^{9}$ There were 31 males and 6 females whose mean age range was $31.08 \pm 12.23$ years. For females, the mean age range was $31.08 \pm 12.23$ years. The mean serum levels of IFN- $\alpha$ were $1.701 \pm 1.16$ and $2.45 \pm 1.44 \mathrm{pg} / \mathrm{dL}$ on days 1 and 5 following admission, respectively. This finding shows that the serum level of IFN- $a$ increased with longer time of admission. The results of this study showed that there was insignificant relation between the serum levels of IFN- $\alpha$ and the age and sex of patients. The patients with overt DIC had lower serum level of IFN- $\alpha$ compared to nonovert DIC $(P<0.001)$. Based on this finding, the serum levels of IFN- $\alpha$ on days 1 and 5 following admission were as low as 1.04 and $1.1 \mathrm{pg} / \mathrm{dL}$ in the patients with overt DIC, respectively. Recently, one study showed the role of cytokines and IFN- $\alpha$ in the pathogenesis of CCHF and found the lower serum levels of IFN- $\alpha$ in the patients with

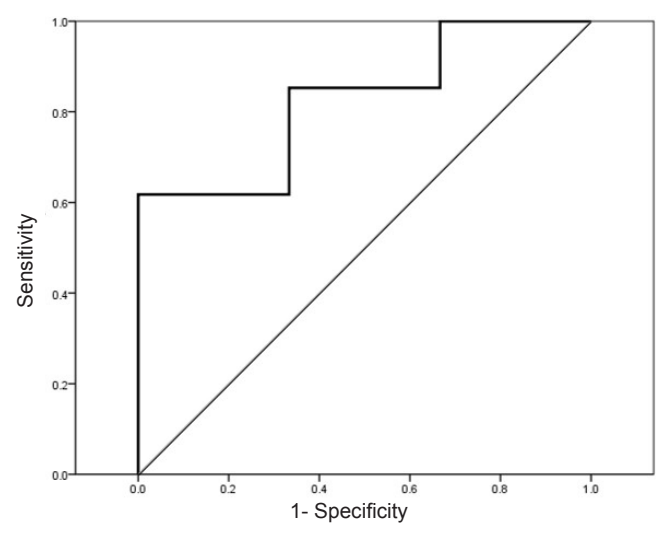

Figure 3. Receiver Operating Characteristics (ROC) Curve in Association With the Performance of the Serum Levels of IFN- $\alpha$ (on Day 1 of Admission) as the Predictor of Final State of Disease.

severe CCHF, though we could not find any human study that reports the role of IFN- $\alpha$ as marker for diagnosis of disease severity. ${ }^{8}$ In vitro study by Karlberg et al compared the antiviral activity of two recombinant IFN- $\alpha$ preparations with a natural IFN- $\alpha$ produced in the human leukocytes and demonstrated that multiferon inhibits viral replication more efficiently than two recombinant IFN- $a$ preparations. The results of this study showed that the sensitivity and specificity of the serum levels of IFN- $\alpha$ on day 1 of admission were $90 \%$ and $88 \%$, respectively. However, the sensitivity and specificity were $83 \%$ and $88 \%$ on day 5 after admission, respectively. ${ }^{13}$ Akinci et al reported that virus by prolonged induction effect on interferon secretion causes blocking of the immune response. ${ }^{14}$ In contrast, Andersson et al reported that IFN- $\alpha$ inhibits progress of the disease and virus replication. ${ }^{15}$ Their finding is inconsistent with our finding.

\section{Conclusion}

The results of this study showed that the higher serum levels of IFN- $\alpha$ in the patients with non-overt DIC, in which virus cannot give rise to decreased severity, is attributed to inhibiting effect of interferon. Conversely, lower serum levels of IFN- $\alpha$ is observed in the patients with overt DIC, in which virus by prolonged induction effect on interferon secretion causes blocking of the immune response.

\section{Ethical Approval}

This study was approved by the Ethics Committee of Zahedan University of Medical Sciences, Zahedan, Iran, under the Thesis No. 586/T.

\section{Competing Interests}

Authors declare that they have no competing interests.

\section{Acknowledgments}

We really thank Dr Metanat for the valuable guidance.

\section{References}

1. Sancakdar E, Güven AS, Uysal EB, et al. Evaluation of cytokines as Th1/Th2 markers in pathogenesis of children 
with Crimean-Congo hemorrhagic fever. Int J clin Exp. 2014;7(3):751-757.

2. Papa A, Dalla VG, Papadimitriou E, Kartalis QN, Antoniadis A. Emergence of Crimean- Congo hemorrhagic fever in Greece. Clin Microbiol Infect. 2010;16(7):843-847. doi:10.1111/j.1469-0691.2009.02996.x.

3. Whitehouse CA. Crimean-Congo hemorrhagic fever. Antiviral Res. 2004;64(3):145-1460. doi:10.1016/j. antiviral.2004.08.001.

4. Ergönül O. Crimean-Congo haemorrhagic fever. Lancet Infect Dis. 2006;6(4):203-214. doi:10.1016/s14733099(06)70435-2.

5. Zivcec M, Safronetz D, Scott D, Robertson S, Ebihara $\mathrm{H}$, Feldmann $\mathrm{H}$. Lethal Crimean-Congo hemorrhagic fever virus infection in interferon alpha/beta receptor knockout mice is associated with high viral loads, proinflammatory responses, and coagulopathy. J Infect Dis. 2013;207(12):1909-1921. doi:10.1093/infdis/jit061.

6. Burney MI, Ghafoor A, Saleen M, Webb PA, Casals J. Nosocomial outbreak of viral hemorrhagic fever caused by Crimean hemorrhagic fever-Congo virus in Pakistan. Am J Trop Med Hyg. 1980;29(5):941-947.

7. Centers for Disease Control and Prevention. Viral hemorrhagic fever: initial management of suspected and confirmed cases. Ann Intern Med. 1984;101(1):73-81. doi:10.7326/0003-4819-101-1-73.

8. Ergonul O, Tuncbilek S, Baykam N, Celikbas A, Dokuzoguz B. Evaluation of serum levels of interleukin (IL6), Il00, and tumornecrosisfactora in patients with Crimean-Congo hemorrhagic fever. J Infect Dis. 2006;193(7):941-944.

9. Jauréguiberry S, Tattevin P, Tarantola A, et al. Imported Crimean Congo Hemrrhagic fever. J Clin Microbiol. 2005;43(9):4905-4907.

10. Taylor FB, Toh CH, Hoots WK, Wada H, Levi M. Towards definition, clinicaland laboratory criteria, and a scoring system for disseminated intravascular coagulation. Thromb Haemost. 2001;86:1327-1330.

11. Papa A, Bino S, Velo E, Harxhi A, Kota M, Antoniadis A. Cytokine levels in Crimean-Congo hemorrhagic fever. J Clin Virol. 2006;36272-276:. doi:10.1016/j.jcv.2006.04.007

12. Mehrabi-Tavana A, Chinikar S, Mazaheri V. The seroepidemiological aspects of Crimean-Congo hemorrhagic fever in three health care workers: a report from Iran. Arch Iran Med 2002;5:255-258.

13. Karlberg H, Lindegren Q, Mirazimi A. Comparison of antiviral activity of recombinant and natural interferons against Crimean-Congo hemorrhagic fever virus. Open Virol J. 2010;4:38-41. doi:10.2174/1874357901004020038.

14. Akinci E, Bodur $H$, Leblebicioglu $H$. Pathogenesis of Crimean congo hemorrhagic fever. Vector Brone Zoonotic Dis Journal 2013;13(7):429-437. doi:10.1089/ vbz.2012.1061.

15. Andersson A, Karlberg H, Mousavi M. Crimean-Congo hemorrhagic fever virus delays activation of the Immune Respons. J Medvirol. 2008;80:1397-1404. doi:10.1002/ jmv.21222. 